\title{
Comentario respecto la prohibición de circos con animales en México: debate social y propuestas legales
}

\section{Elizabeth Montero Romero ${ }^{1}$}

\section{PROHIBICIÓN DE LOS CIRCOS CON ANIMALES EN ESTADOS Y MUNICIPIOS MEXICANOS}

En estos últimos meses la prohibición de los circos con animales en México ha sido un tema de mucho debate entre los mismos mexicanos, ya sea que estén a favor o en contra, y también a nivel internacional.

Pues bien, comenzaremos por referir en qué territorio del país se ha logrado ya implementar la prohibición de este tipo de espectáculo hasta el día de hoy.

Iniciamos señalando a los Estados que han prohibido en todo su territorio los circos, que son: Querétaro, Morelos, Colima, Guerrero, Chiapas, Zacatecas, Distrito Federal, Chihuahua, y recientemente se ha unido a este grupo el estado de Puebla.

Estos espectáculos sólo están prohibidos a nivel municipal en Zapopan y Tlajomulco (Jalisco), Culiacán (Sinaloa), Apodaca (Nuevo León), Naucalpan, Toluca, Atlacomulco (estos tres se hallan en el Estado de México), León (Guanajuato), Tangancícuaro (Michoacán), Teocelo, Xalapa, Boca del Río, Veracruz (todos éstos ubicados en el estado de Veracruz).

A continuación procederé a describir cómo fue el inicio de este movimiento, transcribiendo para ello los argumentos contenidos en los dictámenes de las iniciativas que sirven de base para la citada prohibición de los estados de Querétaro (por ser el primer estado) y de Puebla (el estado más reciente en hacerlo); asimismo, expondré los argumentos que se utilizaron en el municipio de Zapopan, Jalisco (por ser el primer municipio y el "precedente" en prohibir estos espectáculos en todo el país en 2012).

\footnotetext{
${ }^{1}$ Maestranda en el Máster de Derecho Animal y Sociedad (Universitat Autónoma de Barcelona, España) $3^{a}$. Edición.
} 


\subsection{Prohibición de los circos con animales en Querétaro}

En este estado el uso de animales en los circos fue prohibido en el mes de diciembre de 2013.

La iniciativa en dicho estado se presentó el 22 de noviembre de 2013 ante la Comisión de Desarrollo Sustentable, siendo el detonante de esta iniciativa unos sucesos ocurridos en relación con el famoso circo Atayde en el mes de octubre de dicho año en diferentes municipios de ese estado. ${ }^{2}$

Una vez aprobada la iniciativa en la citada Comisión y solicitada su aprobación en sesión del pleno el día 05 de diciembre de 2013, la prohibición de espectáculos circenses que usen animales en Querétaro, quedó establecida por unanimidad de votos ( 25 a favor, 0 abstenciones y 0 en contra), convirtiéndose así en el primer estado mexicano en hacerlo.

A continuación expondré de manera literal el Dictamen de la Iniciativa de Ley que reforma diversas disposiciones de la Ley de Protección Animal del Estado de Querétaro ${ }^{3}$, que presentó la Comisión de Desarrollo Sustentable:

\footnotetext{
2 Entre los detonantes está la difusión de las imágenes de un cadáver de león hallado el 28 de febrero de 2013 en un terreno baldío de Querétaro, cerca de las instalaciones del circo Acuacircus on Parade en la Colonia Satélite; y otro detonante fueron los reclamos contra el Circo Atayde Hermanos por utilizar animales en sus espectáculos a los que se unieron la Cadena de la Asociación Nacional e Internacional contra el Maltrato Animal, quienes denunciaron que dicho circo huyó de Guadalajara con animales previamente asegurados por la PROFEPA debido a las pésimas condiciones de salud en que se encontraban. Cadáver de león tirado por circo indigna en redes sociales (2013, 1 de marzo) Noticias Terra (online). Disponible en:

http://noticias.terra.com.mx/mexico/estados/cadaver-de-leon-tirado-por-circo-indigna-en-redessociales,dc003c208282d310VgnVCM4000009bcceb0aRCRD.html

${ }^{3}$ Dictamen de la Iniciativa de Ley que reforma diversas disposiciones de la Ley de Protección Animal del Estado de Querétaro (Diciembre, 2013) Gaceta legislativa 035. Santiago de Qro.,
} 
"Santiago de Querétaro, Qro., a 04 de diciembre de 2013 Comisión de Desarrollo Sustentable

Asunto: Se rinde dictamen

HONORABLE PLENO DE LA QUINCUAGÉSIMA SÉPTIMA LEGISLATURA DEL ESTADO DE QUERÉTARO

\section{PRESENTE}

Con fecha 02 de diciembre de 2013, fue turnada a la Comisión de Desarrollo Sustentable, para su estudio y dictamen, la "Iniciativa de Ley que reforma $Y$ adiciona diversas disposiciones de la Ley de Protección Animal del Estado de Querétaro" presentada por el Diputado Yairo Marina Alcocer, Coordinador de la Fracción Legislativa del Partido Verde Ecologista de México.

De conformidad con lo dispuesto en los artículos 19, fracción II, de la Constitución Política del Estado de Querétaro, 44, 48, 49, 144, fracción l y 145, fracción VIII, de la Ley Orgánica del Poder Legislativo del Estado de Querétaro, esta Comisión es competente y por ello se abocó al análisis y estudio de las iniciativas de mérito, rindiendo el presente dictamen:

CONSIDERANDO

1. Que de acuerdo a lo establecido por el artículo 7 de la Ley General del Equilibrio Ecológico y Protección al Ambiente, se otorga a las Entidades Federativas la facultad de formulación, conducción y evaluación de la política ambiental estatal, así como la preservación y restauración del equilibrio ecológico en las materias que no estén expresamente atribuidas a la Federación.

2. Que en razón, esta Ley suprema en su artículo 79 , fracción VIII, para la preservación y aprovechamiento sustentable de la flora y fauna silvestre,

Querétaro, México.

pp.30-32.

Disponible en: http://www.legislaturaqueretaro.gob.mx/repositorios/1103.pdf 
considera criterios como "el fomento del trato digno y respetuoso a las especies animales, con el propósito de evitar la crueldad en contra de éstas"

3. Que la Ley General de Vida Silvestre, al hablar del trato digno y respetuoso a la fauna silvestre, otorga facultades a los diferentes niveles de Gobierno, en el ámbito de sus respectivas competencias, en su artículo 29, que a la letra dice: "Los Municipios, las Entidades Federativas y la Federación, adoptarán las medidas de trato digno y respetuoso para evitar o disminuir la tensión, sufrimiento, traumatismo y dolor que se pudiera ocasionar a los ejemplares de fauna silvestre durante su aprovechamiento, traslado, exhibición, cuarentena, entrenamiento, comercialización y sacrificio".

4. Que del mismo modo, en su numeral 30 menciona que "El aprovechamiento de la fauna silvestre se llevará a cabo de manera que se eviten o disminuyan los daños a la fauna silvestre mencionada en el artículo anterior. Queda estrictamente prohibido todo acto de crueldad en contra de la fauna silvestre, en los términos de esta Ley y las normas que de ella deriven".

5. Que conforme al artículo 5 de la Constitución Política del Estado de Querétaro, toda persona tiene derecho a un medio ambiente adecuado para su desarrollo y bienestar integral; que además, es obligación de las autoridades y de los habitantes protegerlo.

6. Que en este contexto, la protección, la conservación, la restauración y la sustentabilidad de los recursos naturales serán tareas prioritarias del Estado.

7. Que en el Estado de Querétaro contamos con la Ley de Protección Animal del Estado de Querétaro, la cual determina la competencia del Poder Ejecutivo del Estado, de las autoridades municipales y la sociedad a impulsar y cumplir principios como el trato digno, el respeto y consideración para todas las especies animales; el promover la cultura de protección y respeto a la naturaleza y erradicar el maltrato y los actos de crueldad con los animales.

8. Que tales leyes consideran como faltas que deben ser sancionadas, los siguientes actos realizados en perjuicio de un animal: toda privación de aire, 
luz, alimento, bebida, espacio suficiente o de abrigo contra la intemperie, que cause o pueda causar daño a un animal.

9. Que no obstante lo anterior, la protección y conservación de los animales en nuestro País continúa rezagada, en este caso debido a la presión ejercida por los dueños de los circos que justifican "la no prohibición de su espectáculo" por el uso necesario de los animales para entretener a la gente, cuando existen circos de alto prestigio mundial que no requieren maltratar animales y cambiar su conducta para divertir a los espectadores. Estos incluso promueven el desempeño humano a través de diversas manifestaciones artísticas, por lo que en nuestro País se podrá continuar sus presentaciones sin la necesidad de utilizar animales para sus actos.

10. Que a nivel mundial países como Suecia, Austria, Costa Rica, India, Finlandia, Venezuela, Colombia, Bolivia, Canadá, Singapur, Ecuador, Perú, Estados Unidos, Argentina, Australia e Israel, han prohibido ya los circos con animales en algunas ciudades y localidades.

11. Que el compromiso ambiental con los animales es una tarea que va más allá de la preservación y rescate de especies amenazadas o en peligro de extinción, incluye también el cuidado y respeto a aquellos con los que convivimos diariamente, desde los animales domésticos, hasta los silvestres en cautiverio y aquellos que errónea e innecesariamente, usamos en espectáculos públicos.

12. Que dado que la Ley debe ser un reflejo del sentir social, es menester modificar el marco jurídico actual a favor del respeto y la protección a la vida de los ejemplares silvestres, exóticos, marinos o domesticables, por lo que como representantes de la ciudadanía debemos velar por los intereses y necesidades de la misma, que mayoritariamente clama la erradicación de los circos con animales.

13. Que en el año 2012, el Municipio de Zapopan, Jalisco se posicionó como el primero que prohibió los circos con animales, al ser aprobada en sesión del 
cabildo la reforma al artículo 63 del Reglamento de Sanidad, Protección y Trato Digno para los Animales, que señala: "Queda estrictamente prohibido el establecimiento con carácter temporal o permanente de espectáculos y circos con animales dentro del Municipio de Zapopan, Jalisco, que ofrezca y utilicen como atractivo principal la explotación, exposición, exhibición y/o participación de animales cualquiera que sea su especie.

14. Que en el presente caso, prohibir la utilización de animales vivos en los circos y espectáculos itinerantes requiere para su cabal implementación, adecuar y reformar también los procedimientos de carácter administrativo, contenidos en los diversos ordenamientos de carácter municipal ya que los Ayuntamientos serán los encargados de imponer las multas a quien incumpla con lo dispuesto en la Ley.

15. Que consecuentemente, resulta obligado reformar la Ley de Protección Animal del Estado de Querétaro, a efecto de que quede establecida, la prohibición en todo el Estado de realizar espectáculos circenses, públicos o privados, en los que se utilicen animales vivos.

16. Que además, con el propósito de armonizar, adecuar y otorgar congruencia entre las determinaciones de la Ley General del Equilibrio Ecológico y Protección al Ambiente y la Ley General de Vida Silvestre en relación al de trato digno y respetuoso a la fauna silvestre y doméstica, con las disposiciones contempladas en nuestra ley local, es que se efectúa la presente reforma. Por lo anteriormente expuesto y fundado, sometemos a la aprobación de esta Representación Popular, los siguientes:

PUNTOS RESOLUTIVOS

Resolutivo Primero. La Comisión de Desarrollo Sustentable aprueba y propone a este Honorable Pleno apruebe, la "Iniciativa de Ley que reforma y adiciona diversas disposiciones de la Ley de Protección Animal del Estado de Querétaro".

Resolutivo Segundo. La Ley aprobada queda en los siguientes términos: 


\section{LEY QUE REFORMA Y ADICIONA DIVERSAS DISPOSICIONES DE LA LEY DE PROTECCIÓN ANIMAL DEL ESTADO DE QUERÉTARO.}

Artículo Único. Se reforman el último párrafo del artículo 37, los artículos 82 y 83, y se adiciona la fracción XIV, del artículo 3 y el artículo 84 bis a la Ley de Protección Animal del Estado de Querétaro, para quedar como sigue:

Artículo 3. Para efectos de...

I. a laXI....

XII. Secretaría: La Secretaría de Desarrollo Sustentable del Estado de Querétaro;

XIII. Unidades de manejo para la conservación de la fauna silvestre: Los predios e instalaciones registrados que operen de conformidad con un plan de manejo aprobado, dentro de los cuales se dé seguimiento al estado del hábitat y de poblaciones o ejemplares que ahi se encuentren;

y XIV. Espectáculo circense: Aquel realizado de manera itinerante dentro de una carpa movible, sin espacio físico fijo para su estancia.

Artículo 37. Son conductas crueles...

Se consideran conductas...

I. a la XXII....

Los espectáculos de tauromaquia, charrería, pelea de gallos y fiestas tradicionales locales, no se considerarán como actos de crueldad o maltrato, para tal efecto del presente artículo, siempre y cuando se realicen conforme a los reglamentos que al efecto emitan las autoridades municipales competentes.

Artículo 82. Los municipios expedirán el permiso para la utilización de animales en festividades públicas o análogas. Si las condiciones de cuidado de los animales se deterioran o se verifican infracciones del permisionario que impliquen crueldad hacia los animales, la autoridad municipal retirará inmediatamente el permiso y procederá a la cancelación del evento. 
Artículo 83. Corresponde a las autoridades federal, estatal y municipal, coordinadas en el ámbito de sus respectivas competencias, vigilar las condiciones en que se encuentren los animales destinados a festividades públicas.

Artículo 84 bis. Queda prohibida la celebración y realización de espectáculos circenses públicos o privados en los cuales se utilicen animales vivos sea cual sea su especie, con fines de explotación, exposición, exhibición y/o participación.

Se sancionará con el equivalente de cinco mil Veces el Salario Mínimo General Diario Vigente en la Zona, a quién celebre o realice clandestinamente espectáculos circenses públicos o privados en los cuales se utilicen animales vivos.

La autoridad municipal hará del conocimiento de la Delegación Estatal de la Procuraduría Federal de Protección al Ambiente, aquellos circos que incumplan con lo dispuesto en el presente artículo, a fin de que instaure el procedimiento administrativo correspondiente, en contra de los propietarios o representantes de los circos y que proceda al aseguramiento precautorio de los ejemplares rescatados, para trasladarlos a los Centros para la Conservación e Investigación de la Vida Silvestre de acuerdo a las leyes federales aplicables.

El presente dictamen fue aprobado en Sesión de la Comisión de Desarrollo Sustentable, del día 04 de diciembre de 2013, con la asistencia de los Diputados Yairo Marina Alcocer, Braulio Mario Guerra Urbiola y Alejandro Bocanegra Montes quienes votaron a favor." (Lo subrayado es mío y tiene la finalidad de enfatizar aspectos relevantes que se tomaron en cuenta). 
Cabe indicar que la mencionada reforma entró en vigor hasta el día 21 de marzo del presente año (2014), cuando ésta se publicó en La Sombra de Arteaga (el Diario Oficial del Estado de Querétaro). ${ }^{4}$

\subsection{Prohibición de los circos con animales en Puebla}

En este estado el uso de animales en los circos fue recientemente prohibido, para ser más exactos el día 22 de julio de 2014.

La Iniciativa de Decreto por el que se reforman, adicionan y derogan diversas disposiciones de la Ley de Protección a los Animales para el Estado de Puebla y del Código Penal del Estado Libre y Soberano de Puebla la presentó el Diputado Juan Carlos Natale, Partido Verde Ecologista de México (PVEM) el día 11 de marzo de 2014. Una vez que fuera aprobada la iniciativa en Comisión el 15 de Julio de 2014 y que se solicitó la aprobación de ésta en sesión del pleno el día 22 de julio de 2014, la prohibición referente a la presentación de circos con animales de cualquier especie en la entidad es ahora una realidad totalmente concreta teniendo 33 votos a favor, 2 en contra ${ }^{5}$ y 2 abstenciones en dicho Pleno.

A continuación expondré literalmente algunos fragmentos de la Iniciativa de Decreto que por virtud del cual se reforman, adicionan y derogan diversas disposiciones de la Ley de Protección a los Animales para el Estado de Puebla y del Código Penal del Estado Libre y Soberano de Puebla ${ }^{6}$, que presentó dicho Diputado:

4 Ley de Protección Animal del Estado de Querétaro. Publicado en "La Sombra de Arteaga" el día 24 de Julio de 2009. Última reforma publicada el día 21 de marzo de 2014. Disponible en: http://www2.queretaro.gob.mx/disco2/servicios/LaSombradeArteaga/2014/20140316-01.pdf

${ }^{5}$ Durante la discusión del dictamen, los diputados Sergio Emilio Gómez Olivier y Pablo Montiel Solana solicitaron se hiciera una discusión exhaustiva sobre el tema, con el propósito de medir los efectos secundarios en la aplicación de la ley, que pudiera repercutir socialmente, como es el de los empresarios del ramo y el de los empleos.

${ }^{6}$ Expongo la iniciativa únicamente pues no se ha publicado en línea el dictamen de aquella iniciativa para poderlo plasmar literalmente en este documento, 
“(...)

Que de acuerdo a la llamada "Lista Roja de la Unión Internacional por la Conservación de la Naturaleza 2013", actualmente existen 20, 940 especies en peligro de extinción a nivel mundial, debido a la cacería, al tráfico ilegal, a la destrucción de los ecosistemas, e incluso a la captura de los animales para diversión o entretenimiento del humano en espectáculos públicos, siendo acciones eminentemente insostenibles y devastadoras para la Biodiversidad.

Que en México, las amenazas arriba señaladas han provocado la extinción de más de 127 especies y del 40\% de la fauna en los últimos veinte años; hoy se encuentran más de 2631 especies listadas en alguna categoría de riesgo en la NOM-059-SEMARNAT-2010.

(...)

Que incluso, La Ley de Protección a los Animales para el Estado de Puebla en su artículo 1 menciona que el objeto de ese ordenamiento es proteger la vida, integridad y desarrollo de los animales, favoreciendo el respeto y buen trato, erradicando los actos de crueldad contra los animales sancionándolos y promover de manera permanente una cultura de protección hacia éstos.

(...)

Que pese a la existencia de este marco jurídico federal y estatal que busca proteger los derechos de los animales y el respeto a su vida digna, las acciones de extrema crueldad que se cometen en contra de la fauna en los

Iniciativa de Decreto que por virtud del cual se reforman, adicionan y derogan diversas disposiciones de la Ley de Protección a los Animales para el Estado de Puebla y del Código Penal del Estado Libre y Soberano de Puebla (Marzo, 2014). Puebla, Puebla, México. Disponible

en: http://www.congresopuebla.gob.mx/index.php?option=com k2\&view=item\&task=download\&id= $\underline{2642}$ 
circos están ampliamente documentadas y nos muestran, como los ejemplares silvestres y/o domésticos, son obligados a realizar rutinas que van en contra de su naturaleza.

Que los trucos que llevan a cabo los animales son penosos, peligrosos y aterradores, y para que los realicen se utilizan diversos objetos como látigos, varillas de fierro o metal, y ganchos con los que los pinchan para obligarlos a actuar. Paralelamente, los métodos de entrenamiento son crueles e irracionales pues se utilizan técnicas de miedo, violencia e intimidación que provocan en los animales mayor enojo, desesperación y ansiedad.

\section{(...)}

Que desafortunadamente, la "legal procedencia y posesión" de los animales silvestres resulta un problema, pues los propietarios de los circos incurren en violaciones a las leyes en comento, alterando los documentos para obtener los permisos de parte de la "SEMARNAT" e introducen de manera ilícita diversas especies, muchas en peligro de extinción.

Resulta importante mencionar, que la violencia ejercida contra los animales en los circos es indigna para todo ser vivo, y las nuevas generaciones requieren de una educación ética, donde valoren y respeten toda manifestación de vida, dejando de ver a los animales como "objetos insensibles" y/o como mercancías sujetas a la apropiación, sometimiento y/o entretenimiento del humano.

Que no obstante lo anterior, la protección y conservación de los animales en nuestro país continúa rezagada, en este caso debido a la presión ejercida por los dueños de los circos que justifican "Ia no prohibicón de su espectáculo" por el uso necesario de los animales para entretener a la gente.

No olvidemos, que el compromiso ambiental con los animales es una tarea que va más alla de la preservación y rescate de especies amenazadas o en 
peligro de extinción. Incluye también el cuidado y respeto a aquellos con los que convivimos diariamente, desde los animales domésticos, hasta aquellos animaes silvestres en cautiverio, y aquellos que errónea $e$ innecesariamente, usamos en espectáculos públicos.

(...)

DECRETO QUE REFORMA, ADICIONA, Y DEROGA DIVERSAS DISPOSICIONES DE LA LEY DE PROTECCIÓN A LOS ANIMALES PARA EL estado de pUEBLA Y del Código penal del estado libre $Y$ SOBERANO DE PUEBLA

PRIMERO.- Se reforman las fracciones V, XII, y XIV del artículo 15, la denominación del Capítulo VIII, el 42, 43 y 45; se Adiciona la fracción XV del artículo 15 y se deroga el último párrafo del artículo 15 y el 41, todos de la Ley de Protección a los Animales para el Estado de Puebla, para quedar como sigue:

ARTÍCULO 3...

Para efectos de la presente Ley, se entenderá por:

(...)

IV.- Se deroga. ${ }^{7}$

(...)

ARTÍCULO 15...

(...)

XIII.- Ofrecer cualquier clase de alimento u objetos a los animales en los centros zoológicos o en exhibiciones cuya ingestión pueda causarles daño físico, enfermedad o muerte, $y$

${ }^{7}$ Originalmente dicha fracción IV de aquel artículo contenía:

“(...) Animal en espectáculos: los animales y especies de fauna silvestre mantenidas en cautiverio que son utilizados para o en un espectáculo público o privado bajo el adiestramiento del ser humano. 
XIV.- Celebrar cualquier tipo de espectáculos públicos o privados en los que se utilicen animales sin importar su especie, con fines de entretenimiento o diversión, incluidos los cirquenses, tauromaquia, peleas de gallos y charrería, quedando exceptuadas las exhibiciones y zoológicos que estarán sujetos a las leyes y reglamentos que se expidan para tal efecto; $y$

(...)

CAPÍTULO VIII

DE LOS ANIMALES EN ESPECTÁCULO

ARTÍCULO 41.- Se deroga. ${ }^{8}$

(...)

Esta reforma aún no entra en vigor puesto que debemos de esperar a que se haga su respectiva publicación. Además se señaló que será hasta dentro de un año aproximadamente que tenga vigencia dicha reforma para que los empresarios del ramo tengan tiempo suficiente para que adapten sus espectáculos conforme a los nuevos lineamientos. Asimismo se estableció que en un plazo no mayor a ciento ochenta días, los doscientos diecisiete ayuntamientos del Estado, deberán modificar su reglamentación para cumplir con lo dispuesto por el presente Decreto.

\subsection{Prohibición de los circos con animales en Zapopan}

Finalmente es el turno de Zapopan, municipio del Estado de Jalisco. Es importante mencionarlo en este comentario puesto que este municipio fue el primero de todos los que se encuentran en este país en establecer la prohibición de los circos con animales.

\footnotetext{
${ }^{8}$ Originalmente este artículo establecía:

"Los propietarios o encargados de los circos deberán contar con los permisos de las autoridades competentes para establecer su espectáculo; el otorgamiento de estos permisos estará supeditado a la presentación de un programa de bienestar animal de conformidad con la legislación de la materia."
} 
La primera iniciativa en este municipio fue presentada el 20 de septiembre de 2010 por la Regidora Gabriela Vázquez Flores, con la finalidad de que ese Ayuntamiento estudiara y en su caso, autorizara abrogar el Reglamento de Sanidad y de Protección a los Animales para el Municipio de Zapopan, Jalisco, y en su lugar se aprobara el Reglamento de Sanidad, Protección y Trato digno para los Animales en el Municipio de Zapopan, Jalisco.

Una vez que los Regidores integrantes de las Comisiones consideraran ${ }^{9}$ en su dictamen procedente abrogar el primer reglamento que he citado en el párrafo anterior se sometió a votación en la sesión de cabildo el día 8 de Junio de 2012 resultando esto en una aprobación exitosa pues se convierte en el primer municipio del país al prohibir estos espectáculos cirquenses con animales dentro de la nueva redacción de dicho reglamento.

A continuación expondré literalmente los fragmentos relacionados a los circos que contiene dicho reglamento: ${ }^{10}$

“(...)

Capitulo XI

De los Circos y Animales de Carga y Tiro

Artículo 63. Queda prohibido el establecimiento con carácter temporal o permanente de espectáculos y circos con animales dentro del Municipio de Zapopan, Jalisco, que ofrezca y utilicen como atractivo principal la explotación,

${ }^{9}$ Dictamen y Propuesta de Comisiones del Ayuntamiento donde se autoriza abrogar el Reglamento de Sanidad y de Protección a los Animales para el Municipio de Zapopan, Jalisco, y aprobar el Reglamento de Sanidad, Protección y Trato Digno para los Animales en el Municipio de Zapopan, Jalisco; así como elevar formal iniciativa al H.Congreso del Estado de Jalisco (Junio, 2012) Zapopan, Jalisco, México. Disponible en: http://zapopan.s3.amazonaws.com/wp-content/uploads/2011/06/308-10-Reglamento-de-

Sanidad-Protecci\%C3\%B3n-y-Trato-Humanitario-para-los-Animal.pdf

${ }^{10}$ Reglamento de sanidad, protección y trato digno para los animales para el municipio de Zapopan. Publicado en la "Gaceta Municipal del Ayuntamiento de Zapopan, Jalisco" el día 03 de Julio de 2012. 
exposición, exhibición y/o participación de animales cualquiera que sea su especie.

En caso de violar esta disposición se procederá a imponer la sanción correspondiente y a la clausura inmediata del circo, en caso de no retirarlo en un término de 24 horas, se realizará el aseguramiento precautorio de los animales, en coordinación con las autoridades competentes para mantenerlos bajo la custodia de la autoridad que corresponda, según la especie.

Evitar el establecimiento con carácter temporal o permanente de espectáculos y circos con animales dentro del Municipio de Zapopan, Jalisco, que ofrezca y utilicen como atractivo principal la explotación, exposición, exhibición y/o participación de animales cualquiera que sea su especie con el fin de salvaguardar el bienestar de los mismos.

$(\ldots)^{\prime \prime}$

Este nuevo reglamento entró en vigor el día 04 de Julio de 2012 cuando se publicó en la Gaceta Municipal del Ayuntamiento de Zapopan.

\section{SITUACIÓN ACTUAL}

Como he comentado previamente hay diversos puntos de vista relacionados con este movimiento de prohibir los circos con animales en México que van desde quien apoya al cien por ciento esta campaña y aplaude la aprobación de las iniciativas en los congresos de los estados o en las sesiones de cabildos en los ayuntamientos, como quien se opone totalmente a esto, entre ellos están los empresarios del ramo y todos las personas que durante toda su vida han dependido de esta industria argumentando que se quedarán sin trabajo ${ }^{11}$, y que no es justamente la mejor situación en este país, donde aun ciertamente es difícil encontrar un sustento económico viable.

\footnotetext{
${ }^{11} \mathrm{http}: / /$ noticieros.televisa.com/mexico/1402/empleo-animales-circos-mexico-parte-1/
} 
Asimismo este movimiento ha provocado muchas manifestaciones así como también ha provocado que la Unión Nacional de Empresarios y Artistas de Circos Mexicanos (Asociación Civil), representada legalmente por Luis Manuel Torres Ramos, presentaran escrito demandando el amparo y la protección de la Justicia Federal Mexicana a raíz de la publicación de la Ley Estatal de Fauna del Estado de Morelos donde se prohíben dichos $\operatorname{circos}^{12}$.

Entre otros argumentos que se escuchan durante las manifestaciones o ruedas de prensas con los empresarios cirquenses está el que más de 200 circos que hay registrados en el país tendrán afectaciones por la ausencia de animales en sus shows: "Si al circo de un cien por ciento que va cuando traes animales si nos los quitan va a ir un 10 o un 20 por ciento y el circo no va a poder subsistir. Ahí nada más estás hablando de alrededor de cinco mil, 10 mil familias que se verían afectadas enormemente por la prohibición de animales", explicó el presidente de la Unión Nacional de Empresarios y Artistas de Circo A.C.

Añaden también los dueños de los circos que están supervisados por la Procuraduría Federal de Protección al Ambiente o que los animales de circo son tratados con dignidad y respeto nunca sufriendo el cambio de libertad a cautividad: "Si un animal no tiene chip vas a la cárcel, si un animal no tiene el procedimiento legal de donde viene, te vas a la cárcel, las multas son arriba de 80 mil pesos, es cárcel fijate, para el domador, para el representante y para el dueño"; "Yo no vi nunca que un grupo de gente de circo fuera a áfrica o fuera a alguna parte a traer animales, en este caso los animales que viven en el circo, ya son 20 generaciones de animales nacidos en cautiverio o en los circos".

Añado a lo anterior, las personas afectadas piden normas que los regulen, pero no que les prohíban trabajar, cuando lo curioso es que ya existen esas normas para regularlos desde hace mucho tiempo y no los cumplen a la cabalidad. Así, si no pueden cumplir

\footnotetext{
12 http://www.derechoanimal.info/esp/page/3182/desestimada-la-impugnacion-de-la-ley-de-faunainterpuesta-por-la-asociacion-de-empresarios-circenses-de-mexico
} 
con esas normas (aparte es notoria la corrupción que existe en este medio para poder adquirir a los animales, sobre todo los animales salvajes) entonces deberían dejar de dedicarse a este espectáculo con animales, puesto que ni se dan "abasto" ni les está haciendo algún bien a los animales pues no cumplen ni con las cinco libertades ${ }^{13}$ que han sido establecidas para que las necesidades de los animales queden cubiertas.

Además los empresarios olvidan que el negocio de los circos con animales ya de por sí estaba en peligro de extinción desde antes de las campañas. Hoy en día la gente asiste al circo muy de vez en cuando y es claro que a un sector importante de la población mexicana es algo que ya no le llama la atención.

Finalmente cabe destacar que el objetivo de prohibir los circos con animales no es ni privar a estas personas de su derecho fundamental a trabajar (artículo 5 de la Constitución Mexicana) ni tampoco privar a los niños mexicanos de las gracias de los animales ni de los payasos, sino los dos objetivos primordiales que debemos tener en cuenta: primero, rescatar a los animales de seguir siendo explotados para realizar trucos ridículos y fuera de su comportamiento natural, convirtiéndolos en payasos ${ }^{14}$ (haciéndolos además pasar por un tormento ante extraños: el público) y segundo, dejar de exhibir a los animales como los prisioneros del ser humano.

Julio 2014

\footnotetext{
${ }^{13}$ 1) que estén libres de sed, hambre y malnutrición; 2) que estén libres de incomodidad; 3) que estén libres de dolor, heridas y enfermedad; 4) que sean libres para expresar su comportamiento normal y 5) que no sufran miedo ni angustia. Estos son los estándares mínimos que el Consejo Británico para el bienestar de animales de granja (FAWC) decidió reconsiderar primeramente para ellos para después extender estos principios hacia toda especie animal.

${ }^{14}$ Tal y como lo podemos ver en la cita perteneciente a la escritora y periodista Ángeles Caso dentro del libro Tamames, K. 2011.Tú también eres un animal. Segunda edición. Madrid: Editorial Manuscritos. pp. 388.
} 